\title{
Desempenho agronômico de cultivares de arroz sob sistema de îrrigação por aspersão e inundação
}

\author{
Eduardo Anibele Streck ${ }^{1} \oplus$, Gabriel Almeida Aguiar ${ }^{\circledR} \oplus$, Paulo Henrique Karling Facchinello ${ }^{3}$, \\ Ariano Martins de Magalhães Júnior ${ }^{4}\left[\right.$, Tuise Kuhn Krüger $^{3}{ }^{\circledR}$, José Maria Barbarat Parfitt ${ }^{4}(\mathbb{0}$

\footnotetext{
1 Instituto Federal Farroupilha, Campus São Vicente do Sul, São Vicente do Sul, RS, Brasil. E-mail: streck.eduardo@gmail.com

2 Instituto Federal do Rio Grande do Sul, Campus Sertão, Sertão, RS, Brasil. E-mail: gabrielalmeidaaguiar@yahoo.com.br

${ }^{3}$ Universidade Federal de Pelotas, Capão do Leão, RS, Brasil. E-mail: phfacchinello@gmail.com; tuisekruger@gmail.com

${ }^{4}$ Embrapa Clima Temperado, Pelotas, RS, Brasil. E-mail: ariano.martins@embrapa.br; jose.parfitt@embrapa.br
}

RESUMO: Atualmente, são necessárias práticas agronômicas que visem melhorar a eficiência do uso da água nas lavouras de arroz irrigado. $O$ estudo teve por objetivo avaliar cultivares de arroz irrigado em sistema de irrigação por inundação e aspersão com uso de pivô linear. $O$ experimento foi conduzido na Embrapa, no Capão do Leão, Rio Grande do Sul (latitude S 31'48'49" e longitude $\left.05^{\circ} 28^{\prime} 20^{\prime \prime}\right)$, nas safras 2011/12 e 2013/14. Implementou-se os sistemas de irrigação por inundação com lâmina de água permanente e o sistema de irrigação por aspersão com pivô linear. Foram avaliados os genótipos BRS Atalanta, BRS Querência, BRS Pampa, BR-IRGA 410, BR-IRGA 409, BRS Sinuelo CL, BRS Fronteira, BRS 7 'Taim', BRS Pampeira e AB $10101 \mathrm{CL}$. Os parâmetros avaliados foram: produtividade de grãos, dias até a floração, estatura de plantas e percentual de grãos inteiros após o beneficiamento. A cultivar BRS Pampa destaca-se na irrigação por aspersão, enquanto que, no sistema de inundação a cultivar BRS Pampeira apresenta maior potencial de produtividade. O sistema de irrigação por aspersão com o uso de pivô linear ocasiona o aumento do ciclo até a floração, redução na estatura de plantas e redução média de $32 \%$ na produtividade de grãos em comparação com o sistema inundado em arroz irrigado.

Palavras-chave: eficiência de irrigação; Oryza sativa L.; pivô linear; produtividade de grãos

\section{Agronomic performance of rice cultivars under sprinkler and flood-irrigation system}

ABSTRACT: Currently, agronomic practices needed to improve the water efficiency use in irrigated rice crops. The study aimed to evaluate rice cultivars in flood and sprinkler-irrigated system with linear pivot. The experiment was conducted at Embrapa,

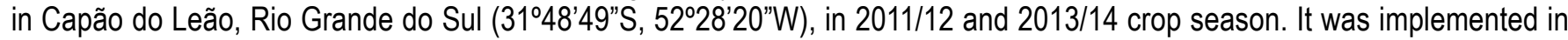
the permanent flood-irrigation systems with water blade and sprinkler-irrigation system with linear pivot. Were evaluated the genotypes BRS Atalanta, BRS Querência, BRS Pampa, BR IRGA 410, BR IRGA 409, BRS Sinuelo CL, BRS Fronteira, BRS 7 'Taim', BRS Pampeira and AB $10101 \mathrm{CL}$. The parameters evaluated were: grain yield, days to flowering, plant height and percentage of entire grains after industrial processing. The cultivar BRS Pampa stands out in sprinkler-irrigation, while in the flood-irrigation system the cultivar BRS Pampeira presents greater yield potential. The sprinkler-irrigation system with the linear pivot results in an increase in cycle to flowering, reduction in plant height and a $32 \%$ reduction in a grain yield compared to flood-irrigation in irrigated rice.

Key words: irrigation efficiency; Oryza sativa L.; linear pivot; grain yield 


\section{Introdução}

O arroz (Oryza sativa L.) é a base da dieta e a principal fonte de proteínas e carboidratos para mais da metade da população mundial (Lee et al., 2011). Logo, a segurança alimentar mundial continuará dependendo da capacidade de sustentar alta produção do cereal (Zeigler \& Barclay, 2008).

Uma parte significativa das crescentes populações de países em desenvolvimento retira seu sustento da agricultura e são, portanto, vulneráveis à efeitos ambientais adversos (Quaye et al., 2012). A escassez de água tornou-se um problema para as áreas de cultivo de arroz irrigado, devido ao declínio da disponibilidade de água doce e a crescente competição por esta água entre as áreas urbanas e a agricultura.

No Brasil, as áreas de cultivo de arroz são predominantemente sob sistema de irrigação por inundação. No Rio Grande do Sul, que atende por aproximadamente $70 \%$ da produção nacional, a orizicultura de sistema irrigado constitui-se em uma das atividades do setor que apresenta a mais alta e estável produtividade. A lavoura arrozeira de sistema irrigado é citada como de grande impacto no uso de água. Os dados disponíveis de uso são variáveis, e o volume aplicado varia de aproximadamente $5.000 \mathrm{~m}^{3} \mathrm{ha}^{-1}$ (Machado et al., 2006; Sartori et al., 2013) chegando a ultrapassar de $15.000 \mathrm{~m}^{3}$ ha $^{-1}$ por safra agrícola (Suárez \& Román, 2016).

No entanto, para se obter uma estimativa da necessidade de água em uma lavoura de arroz irrigado, deve-se considerar a água para se obter a saturação do solo e formação da lâmina, para suprir a evapotranspiração e para compensar as perdas na condução, infiltração e escorrimento superficial.

Estudos recentes mostram que práticas agronômicas que visem reduzir significativamente a quantidade de água utilizada são necessárias para se melhorar a eficiência do uso da água no arroz irrigado (Matsunami et al., 2009; Matsuo \& Mochizuki, 2009). Neste sentido, o sistema de irrigação por aspersão com pivô se torna uma prática a ser amplamente estudada, pois esse sistema pode reduzir pela metade o consumo médio por ciclo de cultivo quando comparado com a irrigação por inundação contínua (Vories et al., 2013; Pinto et al., 2016).

Porém, alguns problemas têm sido relatados na implantação desse sistema de irrigação em arroz irrigado, como difícil controle de plantas daninhas, doenças (Vories et al., 2013). e modificações nos atributos físicos e químicos do solo (Pinto et al., 2016). Esses problemas afetam diretamente a produtividade e prejudicam a adoção por produtores. Para aprimorar e verificar o potencial dessa forma de irrigação é necessário adequar algumas práticas de manejo e cultivares mais adaptadas a esse sistema de irrigação.

Neste contexto, o presente trabalho objetivou avaliar o desempenho agronômico de cultivares de arroz irrigado em sistema de irrigação por inundação e aspersão com uso de pivô linear.

\section{Material e Métodos}

O experimento foi conduzido no campo experimental da Estação de Terras Baixas da Embrapa Clima Temperado

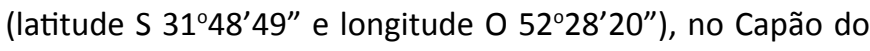
Leão, Rio Grande do Sul, nas safras 2011/12 e 2013/14. O solo da área é do tipo planossolo háplico, com níveis naturais baixos de matéria orgânica, fósforo e de potássio, constituído por argila de classe textural 4.

Foram avaliados dois sistemas de irrigação: o sistema de irrigação por inundação permanente, iniciado aproximadamente aos 20 dias após a emergência (equivalente ao estádio vegetativo de $\mathrm{V}_{4}$ ) até o estádio final de maturação dos grãos (R9); e o sistema de irrigação por aspersão com pivô linear.

Na safra 2011/12, no período compreendido pelo ciclo da cultura, a precipitação média mensal variou entre $66,5 \mathrm{~mm}$ e 169,6 mm. Já para a safra 2013/14 as precipitações médias mensais foram superiores, variando entre $71,8 \mathrm{~mm}$ e 217,1 $\mathrm{mm}$ (Figura 1).

O delineamento foi de blocos casualizados com quatro repetições, sendo as parcelas compostas por nove fileiras de 5 $m$ de comprimento com espaçamento de $0,17 \mathrm{~m}$ entre linhas. A área útil da parcela foi constituída por $4 \mathrm{~m}$ centrais das sete fileiras internas, de modo a minimizar os efeitos de bordadura.

A densidade de semeadura utilizada foi de $120 \mathrm{~kg} \mathrm{ha}^{-1}$, utilizando-se uma semeadora mecânica de parcelas, sob sistema de plantio convencional. A adubação de base foi de $300 \mathrm{~kg} \mathrm{ha}^{-1}$ de NPK (fórmula 5-20-20) e $90 \mathrm{~kg} \mathrm{ha}^{-1}$ de nitrogênio, na forma de uréia, aplicado $50 \%$ da dose no estádio $V_{4}$ e o restante no estádio $\mathrm{R}_{0}$ (diferenciação do primórdio floral).

$O$ controle de plantas daninhas foi efetuado para ambos ensaios através da aplicação de herbicidas pré-emergentes e pós-emergentes, tendo-se levado em consideração as espécies presentes na área. O número de aplicações de pós-emergentes foi maior no sistema de irrigação por aspersão, em decorrência da maior infestação nas áreas. 0 controle de pragas e doenças foram realizadas conforme as recomendações técnicas da cultura.

O monitoramento do nível de água no solo foi realizado através de sensores Watermark, instalados a 0,10 $\mathrm{m}$ de profundidade (considerada a profundidade efetiva do sistema radicular do arroz irrigado). A irrigação ocorria quando a

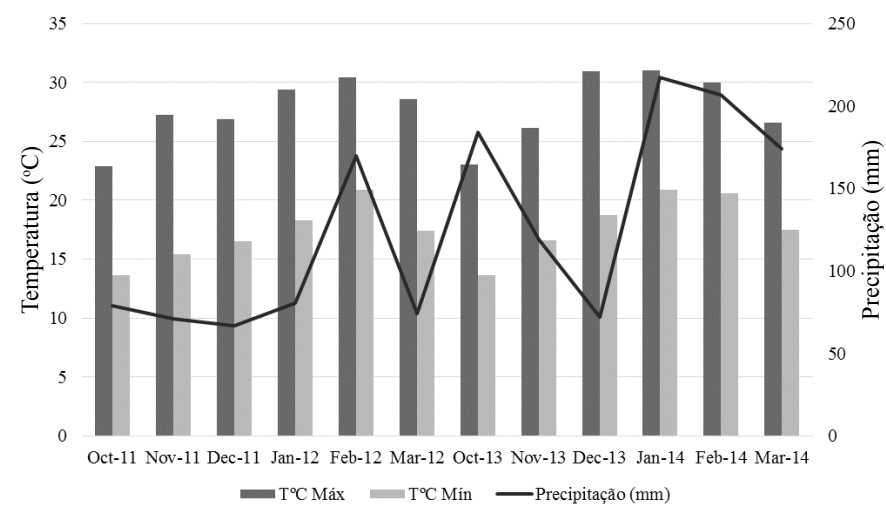

Figura 1. Dados meteorológicos de temperatura mínima mensal ( $\mathrm{T}^{\circ} \mathrm{C}$ Min), temperatura máxima mensal ( $\mathrm{T}^{\circ} \mathrm{C}$ Máx) e precipitação $(\mathrm{mm})$ de ocorrência no período de cultivo do arroz irrigado nas safras 2011/2012 e 2013/2014. 
leitura média da tensão de água no solo era de 40 kPa durante todo o ciclo da cultura.

Foram utilizados neste estudo dez genótipos de arroz irrigado, contemplando nove cultivares de arroz irrigado (BRS Atalanta, BRS Querência, BRS Pampa, BR-IRGA 410, BRIRGA 409, BRS Sinuelo CL, BRS Fronteira, BRS 7 'Taim' e BRS Pampeira) indicadas para o Rio Grande do Sul e uma linhagem híbrida elite do programa de melhoramento genético da Embrapa denominada AB $10101 \mathrm{CL}$.

Os caracteres agronômicos avaliados foram: produtividade de grãos por unidade de área ajustada para 13\% de umidade; número de dias até a floração, considerando-se o número de dias da emergência até $50 \%$ das panículas expostas; estatura de plantas na fase de maturação, que foi obtida medindose a altura do colmo principal do solo até a extremidade da panícula; e percentual de grãos inteiros após o processo de beneficiamento industrial.

As análises estatísticas foram realizadas considerando modelos lineares mistos via REML/BLUP, utilizando o software SELEGEN-REML/BLUP (Resende, 2016).

\section{Resultados e Discussão}

As estimativas dos parâmetros genéticos (Tabela 1), considerando a análise conjunta da avaliação do desempenho agronômico dos 10 genótipos de arroz irrigado, demonstraram existência de efeito de interação dos genótipos diante dos dois diferentes sistemas de irrigação para os caracteres avaliados, pelo do teste qui-quadrado para razão de verossimilhança.

Os coeficientes de herdabilidade individuais e acurácia apresentaram alta magnitude para o caráter de dias até a floração, mas conduziram a coeficientes de magnitudes médios para os caracteres estatura de plantas e percentual de grãos inteiros após o beneficiamento. Logo, esses parâmetros conjuntamente aos baixos coeficientes de variação ambiental, demonstram que a experimentação foi eficiente na minimização dos efeitos ambientais. Entretanto, para o caráter de produtividade de grãos, de herança quantitativa, obtiveram-se baixos coeficientes de herdabilidade e acurácia, decorrente destes coeficientes estarem inflacionados pelas elevadas interações significativas ( $1 \%$ de probabilidade pelo teste qui-quadrado) entre genótipos $x$ anos, genótipos $x$ sistema de irrigação e genótipos $x$ anos $x$ sistema de irrigação.

O desempenho genotípico para o caráter dias até a floração (Tabela 2) indicou um acréscimo expressivo no ciclo dos genótipos no sistema de irrigação por aspersão em comparação ao sistema tradicional de cultivo sob inundação. $O$ incremento foi de 6 dias na média geral dos genótipos avaliados, sendo que, as cultivares BRS Querência, BRS Pampa e BR-IRGA 410 foram as menos afetadas. Este aumento foi detectado com maior intensidade nas cultivares: BRS Atalanta, que apresenta ciclo super-precoce sob cultivo inundado, tendo aumentado em 13 dias seu ciclo até $50 \%$ das panículas emergidas; BRS Sinuelo CL e BRS Pampeira, que apresentam ciclo médio sob cultivo inundado (Magalhães
Tabela 1. Estimativas dos componentes de variância e de parâmetros genéticos para os caracteres de dias até a floração (DAF), estatura de plantas, percentual de grãos inteiros após o beneficiamento industrial (GI) e produtividade de grãos de 10 genótipos de arroz irrigado conduzidos nos sistemas de irrigação sob inundação e por aspersão (pivô linear) nas safras 2011/12 e 2013/14.

\begin{tabular}{|c|c|c|c|c|}
\hline $\begin{array}{c}\text { Componentes } \\
\text { de variância }\end{array}$ & $\begin{array}{l}\text { DAF } \\
\text { (dias) } \\
\end{array}$ & $\begin{array}{c}\begin{array}{c}\text { Estatura } \\
(\mathrm{cm})\end{array} \\
\end{array}$ & $\begin{array}{l}\text { GI } \\
(\%)\end{array}$ & $\begin{array}{c}\text { Produtividade } \\
\left(\mathrm{kg} \mathrm{ha}^{-1}\right)\end{array}$ \\
\hline Deviance & 469,19 & 429,72 & 410,50 & 1475,02 \\
\hline LTR $_{\mathrm{g}}$ & $0,53^{\text {ns }}$ & $0,43^{\text {ns }}$ & $0,50^{\text {ns }}$ & $0,01^{\text {ns }}$ \\
\hline $\mathrm{LTR}_{\mathrm{g} \mid}$ & $28,39 * *$ & $38,45^{* *}$ & $12,28 * *$ & $51,30 * *$ \\
\hline$V_{g}$ & 49,88 & 7,33 & 4,38 & 6558,07 \\
\hline$V_{\text {ga }}$ & 23,07 & 4,07 & 0,11 & 55639,94 \\
\hline$V_{g s}$ & 17,45 & 21,52 & 11,10 & 1035751,66 \\
\hline$V_{e}$ & 15,66 & 11,15 & 13,58 & 412110,32 \\
\hline$V_{f}$ & 106,08 & 44,08 & 29,18 & 1510059,99 \\
\hline$h^{2} g$ & $0,47+-0,18$ & $0,16+-0,10$ & $0,15+-0,10$ & $0,01+-0,01$ \\
\hline $\mathrm{C}^{2}$ ga & 0,21 & 0,09 & 0,01 & 0,03 \\
\hline$c^{2} g s$ & 0,16 & 0,48 & 0,38 & 0,69 \\
\hline$h^{2} \mathrm{mc}$ & 0,83 & 0,39 & 0,43 & 0,02 \\
\hline$A^{c} g$ & 0,91 & 0,64 & 0,66 & 0,11 \\
\hline$r_{g s}$ & 0,74 & 0,25 & 0,28 & 0,01 \\
\hline$r_{g a}$ & 0,68 & 0,64 & 0,97 & 0,10 \\
\hline$r_{\text {gs_a }}$ & 0,80 & 0,34 & 0,29 & 0,05 \\
\hline$r_{\text {ga_s }}$ & 0,74 & 0,87 & 0,99 & 0,95 \\
\hline$r_{g s a}$ & 0,551 & 0,22 & 0,28 & 0,01 \\
\hline $\mathrm{CV}_{\mathrm{gi}}(\%)$ & 7,65 & 3,30 & 3,51 & 1,33 \\
\hline $\mathrm{CV}_{\mathrm{e}}(\%)$ & 4,33 & 4,06 & 6,18 & 10,53 \\
\hline Média geral & 92 & 82,14 & 59,68 & 6.094 \\
\hline
\end{tabular}

LTR - teste de qui-quadrado para razão de verossimilhança dos genótipos; LTR - teste de qui-quadrado para razão de verossimilhança da interação genótipo x sistema de irrigação; *- Significativo pelo teste qui-quadrado a $1 \%$; $V_{\text {- }}$ variância genotípica; $V_{\text {- }}$ - variância da interação genótipos $x$ anos; $V_{g s}$ - variância da interação genótipos $x$ sistema de irrigação; $\mathrm{V}_{\mathrm{e}}$ - variância residual; $\mathrm{V}_{\mathrm{f}}$ - variấncia fenotípica individual; $\mathrm{h}^{2}$ - herdabilidade de parcelas individuais no sentido amplo, ou seja, dos efeitos genotípicos totais; $\mathrm{c}^{2}$ - coeficiente de determinação dos efeitos da interação genótipos $x$ anos; $\mathrm{c}^{2}{ }_{\mathrm{gs}}$ - coeficiente de determinação dos efeitos da interação genótipo $x$ sistema de irrigação; $\mathrm{h}^{2}{ }_{\mathrm{mc}}$-herdabilidade no sentido amplo ao nível de médias de genótipos; $\mathrm{A}^{\mathrm{c}}$ - Acurácia da seleção ao nível de médias de genótipos; $r_{\mathrm{gs}}$ - correlação genotípica entre genótipo $x$ sistema de irrigação; $r_{\mathrm{ga}}$ - correlação genotípica entre genótipo $x$ ano; $r_{p s}$ - correlação genotípica entre genótipo $x$ sistema de irrigação com o ano; $r_{\text {a }}$-correlação genotípica entre genótipo $x$ ano com o sistema de irrigação; $r_{g s a}$-correlação genotípica entre genótipo $x$ ano $x$ sistema de irrigação; $\mathrm{CV}_{\mathrm{gi}}$ coeficiente de variação genotípica; $\mathrm{CV}_{\mathrm{e}}$ - coeficiente de variação residual.

Júnior et al., 2017), que obtiveram acréscimo de 16 e 9 dias, respectivamente, enquadrando-as como ciclo tardio.

Dentre as metas do melhoramento genético de arroz no Sul do Brasil nas últimas décadas, a modificação na duração do ciclo cultural das cultivares foi uma das mais incisivas, tendo-se por base, a redução do ciclo. Portanto, para aumentar as chances de escape do problema do frio, as épocas de semeadura e o ciclo devem ser escolhidos de modo que a floração, que é uma das fases mais críticas da planta às baixas temperaturas, não coincida com o período de maiores chances de ocorrência destas temperaturas (Campos et al., 2008). Logo, ciclos muito prolongados como no exposto das cultivares BRS Sinuelo $\mathrm{CL}$ e BRS Pampeira no cultivo sob sistema de aspersão, devem ser evitados para que suas florações não ocorram durante este período crítico.

Os valores positivos e negativos da interação genótipo $\mathrm{x}$ sistema de irrigação indicam, respectivamente, se o sistema foi favorável ou desfavorável ao referido genótipo, possibilitando aumentar ou não a performance genotípica para o caráter 
Tabela 2. Desempenho genotípico (u+g+ge), índice de variação $(\triangle D A F)$ e valores da interação genótipo $x$ sistema de irrigação para o caráter de dias até a floração de 10 genótipos de arroz irrigado avaliados nas safras 2011/12 e 2013/14.

\begin{tabular}{|c|c|c|c|c|c|c|}
\hline \multirow{2}{*}{ Genótipo } & \multicolumn{2}{|c|}{$u+g+g e$} & \multirow{2}{*}{$\triangle \mathrm{DAF}$} & \multicolumn{2}{|c|}{ Interação G X S } & \multirow[b]{2}{*}{ Média geral } \\
\hline & Aspersão & Inundação & & Aspersão & Inundação & \\
\hline BRS Atalanta & 83 & 70 & 13 & 0,71 & $-5,34$ & 77 \\
\hline BRS Querência & 88 & 87 & 1 & $-3,60$ & 2,12 & 87 \\
\hline BRS Pampa & 90 & 89 & 1 & $-3,15$ & 2,46 & 90 \\
\hline BR-IRGA 410 & 94 & 95 & -1 & $-3,17$ & 3,90 & 95 \\
\hline BR-IRGA 409 & 99 & 91 & 8 & 0,87 & $-0,01$ & 95 \\
\hline BRS Sinuelo CL & 104 & 88 & 16 & 5,23 & $-4,08$ & 96 \\
\hline BRS Fronteira & 97 & 94 & 3 & $-1,35$ & 2,26 & 95 \\
\hline BRS 7 'Taim' & 97 & 90 & 7 & 0,72 & $-0,31$ & 93 \\
\hline AB $10101 \mathrm{CL}$ & 96 & 87 & 9 & 1,14 & $-1,22$ & 92 \\
\hline BRS Pampeira & 106 & 97 & 9 & 2,59 & 0,21 & 101 \\
\hline Média Geral & 95 & 89 & 6 & - & - & 92 \\
\hline
\end{tabular}

em referência. Neste sentido, observa-se que a cultivar BRS Sinuelo $\mathrm{CL}$ foi a mais afetada pela alteração nos sistemas de irrigação para este parâmetro.

Os genótipos demonstraram expressiva redução para o parâmetro estatura de plantas (Tabela 3) no sistema de irrigação por aspersão, quando comparado ao cultivo em inundação. Os genótipos apresentaram estatura média de $94,2 \mathrm{~cm}$ no sistema com inundação, contraposto aos $70,1 \mathrm{~cm}$ de média obtida no sistema de irrigação por aspersão. Logo, houve uma redução média de aproximadamente $25 \%(24 \mathrm{~cm})$ na estatura de plantas no sistema de pivô linear.

O índice de variação para estatura de plantas evidenciou flutuações de 13,7 cm, para a cultivar BRS Querência, até $34,5 \mathrm{~cm}$, para a BRS Fronteira. Isto demonstra a elevada interação genótipo $x$ ambiente para este parâmetro. Este desempenho genotípico corrobora com McCauley (1990) que comparou a irrigação por inundação com sistema de irrigação por aspersão, através da avaliação de 12 cultivares de arroz irrigado no Texas, verificando uma redução de 9 a $28 \mathrm{~cm}$ na estatura das plantas no sistema de irrigação por aspersão.

Estas alterações morfológicas verificadas podem restringir a translocação dos fotoassimilados para os grãos e afetar a expressão do potencial produtivo do genótipo. Na Tabela 4 são apresentados os desempenhos de produtividade dos genótipos frente aos sistemas de irrigação.

O desempenho genotípico de produtividade de grãos dos genótipos determinou redução média de $2.315 \mathrm{~kg} \mathrm{ha}^{-1}$
$(31,93 \%)$ no sistema de irrigação por aspersão em comparação com o inundado. A média genotípica geral nas duas safras agrícolas foi de $7.252 \mathrm{~kg} \mathrm{ha}^{-1}$ para o sistema de irrigação por inundação e $4.936 \mathrm{~kg} \mathrm{ha}^{-1}$ no cultivo sob aspersão. Valores parecidos foram verificados por Westcott \& Vines (1986), que encontraram rendimentos médios de $5.901 \mathrm{~kg} \mathrm{ha}^{-1}$ sob irrigação por aspersão e $7.846 \mathrm{~kg} \mathrm{ha}^{-1}$ sob irrigação por inundação. McCauley (1990) também evidenciou reduções médias de produtividade acima de $20 \%$ no sistema por aspersão.

Em relação ao desempenho genotípico relativo aos genótipos, a cultivar que melhor se destacou no sistema sob irrigação por aspersão foi a BRS Pampa com produtividade média de $6.438 \mathrm{~kg} \mathrm{ha}^{-1}$. Além disso, a BRS Pampa demonstrou os melhores índices de adaptabilidade e estabilidade genotípica.

As cultivares BRS Pampa, BR-IRGA 410 e BRS Querência foram as cultivares com menores índices de variação para a produtividade no comparativo dos sistemas de irrigação. Já a cultivar BRS Pampeira apresentou elevada produtividade no sistema de inundação (9.494 kg ha-1), no entanto, demonstrou ser altamente influenciada pela restrição hídrica, representada pela redução de $6.021 \mathrm{~kg} \mathrm{ha}^{-1}(63 \%)$. Esses resultados corroboram com Streck et al. (2018), que verificaram que essa cultivar é altamente responsiva às melhorias do ambiente, sendo indicada para condições de alta tecnologia As médias de produtividade de arroz irrigado com inundação no RS nas

Tabela 3. Desempenho genotípico ( $u+g+g e$ ), índice de variação ( $\Delta$ Est) e valores da interação genótipo $x$ sistema de irrigação (G x S) de 10 genótipos de arroz irrigado avaliados para o caráter de estatura de plantas nas safras 2011/12 e 2013/14.

\begin{tabular}{lccccccc}
\hline \multirow{2}{*}{ Genótipo } & \multicolumn{2}{c}{ U+g+ge } & \multirow{2}{*}{$\boldsymbol{N}$ Est } & \multicolumn{2}{c}{ Interação $\mathbf{~ x ~ S ~}$} & \multirow{2}{*}{ Média geral } \\
\cline { 2 - 3 } & Aspersão & Inundação & & Aspersão & Inundação & \\
\hline BRS Atalanta & 68,52 & 93,52 & $-25,00$ & $-1,13$ & $-0,20$ & 89,07 \\
BRS Querência & 82,20 & 95,94 & $-13,74$ & & 9,27 & $-1,04$ & 85,24 \\
BRS Pampa & 76,40 & 94,09 & $-17,69$ & & 5,03 & $-1,34$ & 84,58 \\
BR-IRGA 410 & 66,94 & 99,19 & $-32,25$ & $-3,54$ & 4,63 & 83,47 \\
BR-IRGA 409 & 73,64 & 95,53 & $-21,89$ & 2,53 & 0,35 & 83,06 \\
BRS Sinuelo CL & 64,60 & 86,06 & $-21,47$ & $-2,75$ & $-5,35$ & 81,02 \\
BRS Fronteira & 66,21 & 100,72 & $-34,51$ & $-4,43$ & 6,00 & 80,95 \\
BRS 7 'Taim' & 67,68 & 89,94 & $-22,26$ & $-1,08$ & $-2,89$ & 79,95 \\
AB 10101 CL & 68,53 & 93,37 & $-24,84$ & $-1,09$ & $-0,32$ & 78,81 \\
BRS Pampeira & 66,42 & 93,48 & $-27,06$ & $-2,79$ & 0,18 & 75,33 \\
Média Geral & 70,11 & 94,18 & $-24,07$ & - & - & 82,15 \\
\hline
\end{tabular}


Tabela 4. Desempenho genotípico (u+g+ge), índice de variação ( $\Delta$ Prod), valores da interação genótipo x sistema de irrigação ( $\mathrm{G} \times \mathrm{S}$ ) e adaptabilidade e estabilidade de 10 genótipos de arroz irrigado avaliados para o caráter de produtividade de grãos (kg ha $^{-1}$ ) nas safras 2011/12 e 2013/14.

\begin{tabular}{|c|c|c|c|c|c|c|c|c|}
\hline \multirow{2}{*}{ Genótipo } & \multicolumn{2}{|c|}{$u+g+g e$} & \multirow{2}{*}{$\Delta$ Est } & \multicolumn{2}{|c|}{ Interação G x E } & \multirow{2}{*}{ Média geral } & \multirow{2}{*}{ MHPRVG } & \multirow{2}{*}{ MHPRVG*MG } \\
\hline & Aspersão & Inundação & & Aspersão & Inundação & & & \\
\hline BRS Atalanta & 4.010 & 6.804 & -2.793 & -917 & -439 & 5.405 & 0.8709 & 5.307 \\
\hline BRS Querência & 4.800 & 5.749 & -949 & -126 & -1.492 & 5.273 & 0.8735 & 5.323 \\
\hline BRS Pampa & 6.438 & 7.889 & -1.452 & 1.489 & 624 & 7.166 & 1.1864 & 7.229 \\
\hline BR IRGA 410 & 5.736 & 6.447 & -711 & 800 & -805 & 6.091 & 1.0074 & 6.139 \\
\hline BR IRGA 409 & 4.725 & 7.354 & -2.629 & -210 & 104 & 6.040 & 0.9849 & 6.002 \\
\hline BRS Sinuelo CL & 4.702 & 7.549 & -2.848 & -235 & 297 & 6.126 & 0.9948 & 6.062 \\
\hline BRS Fronteira & 5.551 & 7.501 & -1.950 & 610 & 244 & 6.527 & 1.0776 & 6.567 \\
\hline BRS 7 'Taim' & 5.062 & 7.642 & -2.580 & 123 & 387 & 6.353 & 1.0396 & 6.335 \\
\hline AB $10101 \mathrm{CL}$ & 4.861 & 6.086 & -1.225 & -67 & -1.157 & 5.472 & 0.9063 & 5.523 \\
\hline BRS Pampeira & 3.473 & 9.494 & -6.021 & -1.468 & 2.237 & 6.484 & 0.9153 & 5.577 \\
\hline Média Geral & 4.936 & 7.252 & -2.316 & & & 6.094 & & \\
\hline
\end{tabular}

safras 2011/12 e 2013/14, referente àquelas em que foram conduzidos os experimentos foram, $7.350 \mathrm{~kg} \mathrm{ha}^{-1}$ e $7.243 \mathrm{~kg} \mathrm{ha}^{-1}$, respectivamente, próximos às médias obtidas no presente trabalho. No entanto, salienta-se que muitas destas cultivares têm potencial produtivo maior que os apresentados, podendo assim, alterar a relação entre os sistemas de irrigação.

Além destes atributos agronômicos, a qualidade dos grãos em arroz é de fundamental importância, pois fornece parâmetros importantes para o conhecimento do produto final após o processo de cocção. Sendo que, a maior parte dos componentes do arroz polido é composta por amido (até $95 \%$ do peso seco), proteína (5 a 7\%) e lipídeos (0,5 a 1\%). A quantidade destes compostos pode afetar as propriedades sensoriais (Fitzgerald et al., 2008).

Um aspecto importante é que a disponibilidade de água no solo favorece a translocação dos fotoassimilados para os grãos, afetando a formação dos grãos e os teores de nutrientes (Crusciol et al., 2007).

O desempenho genotípico dos genótipos quanto ao rendimento de grãos inteiros após o beneficiamento (Tabela 5), demonstrou leve incremento na condição de aspersão em relação ao cultivo inundado. Esses resultados contrariam as

Tabela 5. Desempenho genotípico (u+g+ge) e valores da interação genótipo $\times$ sistema de irrigação $(G \times S)$ de 10 genótipos de arroz irrigado avaliados para o caráter de percentual de grãos inteiros após o beneficiamento industrial nas safras 2011/12 e 2013/14.

\begin{tabular}{lccccc}
\hline \multirow{2}{*}{ Genótipo } & \multicolumn{2}{c}{ u+g+ge } & \multicolumn{2}{c}{ Interação G x S } & Média \\
\cline { 2 - 5 } & Aspersão & Inundação & Aspersão & Inundaçãon & geral \\
\hline BRS Atalanta & 65,13 & 62,46 & 1,41 & 3,18 & 63,79 \\
BRS Querência & 59,12 & 49,77 & $-0,47$ & $-5,37$ & 54,44 \\
BRS Pampa & 62,89 & 59,50 & 0,31 & 1,37 & 61,19 \\
BR-IRGA 410 & 61,62 & 58,97 & $-0,55$ & 1,24 & 60,29 \\
BR-IRGA 409 & 61,99 & 60,76 & $-0,66$ & 2,56 & 61,37 \\
BRS Sinuelo CL & 61,28 & 60,14 & $-1,08$ & 2,23 & 60,71 \\
BRS Fronteira & 62,24 & 59,70 & $-0,23$ & 1,67 & 60,97 \\
BRS 7 'Taim' & 61,87 & 60,63 & $-0,73$ & 2,48 & 61,25 \\
AB 10101 CL & 63,61 & 49,86 & 3,00 & $-6,29$ & 56,74 \\
BRS Pampeira & 59,30 & 52,74 & $-0,98$ & $-3,09$ & 56,02 \\
Média geral & 61,90 & 57,45 & - & - & 59,68 \\
\hline
\end{tabular}

evidências de Guimarães et al. (2011) sobre a importância do suprimento adequado de água para a formação e melhoria da qualidade dos grãos. Crusciol et al. (2006), verificaram que disponibilidade adequada de água proporciona a maior translocação de carboidratos para os grãos, que, bem formados, possuem maior resistência a choques e vibrações proporcionadas pela colheita e pelo beneficiamento, obtendose, assim, maior rendimento de grãos inteiros.

No entanto, esta característica de qualidade encontra-se altamente condicionada às características genéticas da cultivar, época e métodos de colheita e secagem dos grãos. Além disso, as condições climáticas específicas na floração e no enchimento dos grãos podem influenciar diretamente este atributo.

Conciliando os resultados dos caracteres agronômicos e de qualidade avaliados, pode-se observar que para as condições do sul do Rio Grande do Sul, com solo típico hidromórfico caracterizado pelo horizonte $A$ bastante raso e horizonte $B$ textural, a irrigação por aspersão com o uso de pivô linear em arroz irrigado pode diminuir o uso de água, mas ele ocasiona aumento dos dias até a floração e redução na estatura de plantas e produtividade de grãos.

Além disso, a irrigação por aspersão em arroz irrigado aumenta a necessidade de herbicidas e fungicidas em comparação com irrigação por inundação (Westcott \& Vines, 1986). A manutenção de lâmina de água no sistema inundado, também possibilita alguns efeitos benéficos no controle de plantas daninhas (Villa et al., 2006) e aumento da disponibilidade de nutrientes devido às alterações do $\mathrm{pH}$ da solução do solo (Silva et al., 2008) que são fatores altamente limitantes de produtividade na cultura do arroz irrigado. Isto ocorre, pois, a lâmina de água sobre o solo funciona como barreira física, impedindo a germinação das sementes das plantas daninhas devido à redução de oxigênio (Villa et al., 2006).

Segundo Cavero et al. (2011) o controle de plantas daninhas é o principal desafio cultural encontrado para cultivar arroz sob irrigação por aspersão, devendo ser realizado o controle desde os primeiros estádios de desenvolvimento de arroz. Outros estudos também relatam evidências na concorrência de plantas daninhas, como por exemplo, o capim arroz, que aumenta sua ocorrência à medida que a profundidade e 
duração de inundação diminuiu (Agostinetto et al., 2007; Rao et al., 2007). Outra mudança observada entre os sistemas de irrigação diz respeito à incidência de insetos praga. No sistema de aspersão não há ataque de Oryzophagus oryzae (gorgulhoaquático ou bicheira-da-raiz), que se desenvolve com lâmina de água atacando o sistema radicular do arroz.

Além disso, a produtividade do arroz irrigado por aspersão diminui com o aumento da macroporosidade do solo, e é favorecida com o aumento na disponibilidade de fósforo e potássio (Pinto et al., 2016).

Vale ressaltar que houve uma grande variação na resposta genotípica das cultivares avaliadas, destacando-se para o cultivo em sistema de irrigação por aspersão a cultivar BRS Pampa. No entanto, o arroz apresenta uma ampla variabilidade genética, podendo assim, surgir genótipos amplamente adaptados e com maior eficiência agronômica neste sistema de irrigação por aspersão.

\section{Conclusões}

O sistema de irrigação por aspersão com o uso de pivô linear ocasiona o aumento do ciclo até a floração, redução na estatura de plantas e redução média de $32 \%$ na produtividade de grãos em comparação com o sistema inundado em arroz irrigado.

A cultivar BRS Pampa destaca-se na irrigação por aspersão, enquanto que, no sistema de inundação a cultivar BRS Pampeira apresenta maior potencial de produtividade.

\section{Agradecimentos}

À Embrapa Clima Temperado pelo aporte de infraestrutura e fornecimento de sementes.

\section{Literatura Citada}

Agostinetto, D.; Galon, L.; Moraes, P.V.D.; Tironi, S.P.; Dalmagro, T.; Vignolo, G.K. Interferência de capim-arroz (Echinochloa spp.) na cultura do arroz irrigado (Oryza sativa) em função da época de irrigação. Planta Daninha, v.25, n.4, p.689-696, 2007. https://doi. org/10.1590/S0100-83582007000400005.

Campos, C.R.J.; Fernandes, D.S.; Machado, R.; Silva, J.B. Relação entre a passagem de sistemas frontais e a ocorrência de baixas temperaturas durante as fases de pré-floração e floração do arroz irrigado no RS. Revista Brasileira Agrociência, v.14, n.3-4, p.188-194, 2008. https://doi.org/10.18539/cast.v14i3.1948.

Cavero, J.; Zaragoza, C.; Cirujeda, A.; Anzalone, A.; Faci, J.M.; Blanco, O. Selectivity and weed control efficacy of some herbicides applied to sprinkler irrigated rice (Oryza sativa L.). Spanish Journal of Agricultural Research v.9, n.2, p.597-605, 2011. https://doi. org/10.5424/sjar/20110902-159-10.

Crusciol, C.A.C.; Soratto, R.P.; Arf, O. Produtividade de grãos e exportação de nutrientes de cultivares de arroz irrigadas por aspersão em consequência da época de semeadura. Bragantia, v.66, n.2, p.247-257, 2007. https://doi.org/10.1590/s000687052007000200008 .
Crusciol, C.A.C.; Soratto, R.P.; ARF, O.; Mateus, G.P. Yield of upland rice cultivars in rainfed and sprinkler-irrigated systems in the Cerrado region of Brazil. Australian Journal of Experimental Agriculture, v.46, n.11, p.1515-1520, 2006. https://doi.org/10.1071/EA04035.

Fitzgerald, M.A.; Hamilton, N.R.S.; Calingacion, M.N.; Verhoeven, H.A.; Butardo, V.M. Is there a second gene for fragrance in rice? Plant Biotechnology Journal, v.6, n.4, p.416-423, 2008. https:// doi.org/10.1111/j.1467-7652.2008.00327.x.

Guimarães, C.M. Stone, L.F.; Oliveira, J.P.; Rangel, P.H.N.; Rodrigues, C.A.P. Sistema radicular do arroz de terras altas sob deficiência hídrica. Pesquisa Agropecuária Tropical, v.41, n.1, p.126-134, 2011. https://doi.org/10.5216/pat.v41i1.8460.

Lee, I.; Seo, Y.S.; Coltrane, D.; Hwang, S.; Oh, T.; Marcotte, E.M.; Ronald, P.C. Genetic dissection of the biotic stress response using a genome-scale gene network for rice. Proceedings of the National Academy of Sciences, v.108, n. 45, p.18548-18553, 2011. https://doi.org/10.1073/pnas.1110384108.

Machado, S.L.O.; Marchezan, E.; Righes, A.A.; Carlesso, R.; Villa, S.C.C.; Camargo, E.R. Consumo de água e perdas de nutrientes e de sedimentos na água de drenagem inicial de arroz irrigado. Ciência Rural, v.36, n.1, p. 65-71, 2006. https://doi.org/10.1590/ S0103-84782006000100010.

Magalhães Júnior, A.M. de; Morais, O.P. de; Fagundes, P.R.R.; Colombari Filho, J.M.; Franco, D.F.; Cordeiro, A.C.C.; Pereira, J.A.; Rangel, P.H.N.; Moura Neto, F.P.; Streck, E.A.; Aguiar, G.A.; Facchinello, P.H.K. BRS Pampeira: new irrigated rice cultivar with high yield potential. Crop Breeding and Applied Biotechnology, v.17, n.1, p.78-83, 2017. https://doi.org/10.1590/1984-70332017v17n1c13.

Matsunami, M.; Matsunami, T.; Kokubun, M. Growth and yield of new rice for Africa (NERICAs) under different ecosystems and nutrient levels. Plant Production Science, v.12, n.3, p.381-389, 2009. https://doi.org/10.1626/pps.12.381.

Matsuo, N.; Mochizuki, T. Growth and yield of six rice cultivars under three water-saving cultivations. Plant Production Science, v.12, n.4, p.514-525, 2009. https://doi.org/10.1626/pps.12.514.

McCauley, G.N. Sprinkler vs. flood irrigation in traditional rice production regions of Southeast Texas. Agronomy Journal, v.82, n.4, p.677-683, 1990. https://doi.org/10.2134/agronj1990.0002 1962008200040006x.

Pinto, M.A.B.; Parfitt, J.M.B.; Timm, L.C.; Faria, L.C.; Scivittaro, W.B. Produtividade de arroz irrigado por aspersão em terras baixas em função da disponibilidade de água e de atributos do solo. Pesquisa Agropecuária Brasileira, v.51, n.9, p.1584-1593, 2016. https://doi.org/10.1590/S0100-204X2016000900058.

Quaye, W.; Yawson, R.M.; Ayeh, E. S.; Yawson, I. Climate change and food security: The role of biotechnology. African Journal of Food, Agriculture, Nutrition and Development, v.12, n.5, p.6354-6364, 2012. http://ssrn.com/abstract=2133268. 08 Mai. 2016.

Rao, A.N.; Johnson, D.E.; Sivaprasad, B.; Ladha, J.K.; Mortimer, A.M. Weed management in direct-seeded rice. Advances in Agronomy, v. 91, p. 153-255, 2007. https://doi.org/10.1016/ s0065-2113(06)93004-1.

Resende, M.D.V. Software Selegen-REML/BLUP: a useful tool for plant breeding. Crop Breeding and Applied Biotechnology, v.16, n.4, p.330-339, 2016. https://doi.org/10.1590/1984$70332016 v 16 n 4 a 49$. 
Sartori, G.M.S.; Marchesan, E.; Azevedo, C.F.; Streck, N.A.; Roso, R.; Coelho, L.L.; Oliveira, M.L. de. Rendimento de grãos e eficiência no uso de água de arroz irrigado em função da época de semeadura. Ciência Rural, v.43, n.3, p.397-403, 2013. https://doi. org/10.1590/S0103-84782013000300004.

Silva, L.S.; Ranno, S.K.; Rhoden, A.C.; Santos, D.R.; Graupe, F.A. Avaliação de métodos para estimativa da disponibilidade de fósforo para arroz em solos de várzea do Rio Grande do Sul. Revista Brasileira de Ciência do Solo, v.32, n.1, p.207-216, 2008. https://doi.org/10.1590/S0100-06832008000100020.

Streck, E.A.; Magalhães Júnior, A.M. de; Fagundes, P.R.R.; Aguiar, G.A.; Facchinello, P.H.K.; Oliveira, A.C.de. Adaptability and stability of flood-irrigated rice cultivars released to the subtropical region of Brazil. Pesquisa Agropecuária Brasileira, v.53, n.10, p.1140-1149, 2018. https://doi.org/10.1590/s0100$204 \times 2018001000007$.
Suárez, D.F.P.; Román, R.M.S. Consumo de água em arroz irrigado por inundação em sistema de múltiplas entradas. Irriga, v.1, n.1, p.78-95, 2016. https://doi.org/10.15809/irriga.2016v1n1p78-95.

Villa, S.C.C.; Marchezan, E.; Massoni, P.F.S.; Santos, F.M.; Avila, L.A.; Machado, S.L.O.; Telo, G.M. Controle de arroz vermelho em dois genótipos de arroz (Oryza sativa) tolerantes a herbicidas do grupo das imidazolinonas. Planta Daninha, v.24, n.3, p.549-555, 2006. https://doi.org/10.1590/S0100-83582006000300018.

Vories, E.D.; Stevens, W.E.; Tacker, P.L.; Griffin, T.W.; Counce, P.A. Rice production with center pivot irrigation. Applied Engineering in Agriculture, v.29, n.1, p.51-60, 2013. https://doi. org/10.13031/2013.42532.

Westcott, M.P.; Vines, K.W.A Comparison of Sprinkler and Flood Irrigation for Rice. Agronomy Journal, v.78, n.4, p.637-640, 1986. https://doi.org/10.2134/agronj1986.00021962007800040016x.

Zeigler, R.S.; Barclay, A. The relevance of rice. Rice, v.1, n.1, p.3-10, 2008. https://doi.org/10.1007/s12284-008-9001-z. 